\title{
Regeneration of the Auditory Midbrain Intercommissural Projection in Organotypic Culture
}

\author{
Aziz Hafidi,' Dan H. Sanes, ${ }^{1}$ and Dean E. Hillman' \\ ${ }^{1}$ Center for Neural Science and Department of Biology, New York University, New York, New York 10003 and \\ 2Departments of Otolaryngology and Physiology and Biophysics, New York University School of Medicine, New York, \\ New York 10016
}

\begin{abstract}
The aim of this study was to determine whether postnatal mammalian central neurons retain the capacity for axonal regeneration across a lesion site in organotypic cultures of the auditory midbrain. Brain slices from the gerbil inferior colliculus (IC) were obtained from postnatal 6-8 d old animal and cultured for 6-15 $d$ in vitro. IC explants containing an intact commissural projection exhibited robust axonal and dendritic morphologies as assessed with biocytin labelling. In transected explants, the two lobes of the inferior colliculus were cut at the midline and then reapposed to one another in vitro. There was a robust regeneration of commissural fibers across the lesion site in $78 \%$ of the biocytin-labeled explants. Massive axonal regeneration was also revealed by immunostaining explants for Tau (100\% of sections), an axon-specific microtubule-associated protein. Ultrastructural analyses demonstrated that biocytin-labeled regenerating fibers established de novo synaptic profiles in the contralateral lobe of the inferior colliculus. Finally, the distribution of astrocytes and oligodendrocytes were assessed by staining for glial fibrillary acidic protein (GFAP) and myelin-associated glycoprotein (MAG), respectively. GFAP-positive astrocytes were more widely distributed than in vivo, and oligodendrocytes remained immature, and evenly distributed in all explants. Taken together, these data demonstrate that the postnatal mammalian auditory midbrain can be maintained in vitro, and that central axons are capable of regenerating across the site of injury without the aid of an artificial substrate.
\end{abstract}

[Key words: inferior colliculus, regeneration, commissure, synaptogenesis, organotypic culture, gerbil, auditory]

Adult mammalian central neurons fail to regenerate axonal processes following injury (Ramón y Cajal, 1928; Aguayo, 1985), although retinotectal projections of fish and amphibia are fully capable of such regrowth (Matthey, 1925; Piatt, 1956). The failure of mammalian central neurons to regenerate axonal projections may stem from the absence of growth-permissive sig-

\footnotetext{
Received Mar. 16, 1994; revised July 21, 1994; accepted Aug. 3, 1994.

We gratefully acknowledge Ursula Koch for her assistance with the dextranbiotin labeling experiment, Drs. A. Fellous and $\mathrm{M}$. Schachner for providing antiserum, and Byron Taylor for photographic assistance. This work was partially sponsored by NIH DC00540 (D.H.S.) and NS13742 (D.E.H.).

Correspondence should be addressed to Dan H. Sanes, Center for Neural Science, 6 Washington Place, New York University, New York, NY 10003.

Copyright (c) 1995 Society for Neuroscience $0270-6474 / 95 / 151298-10 \$ 05.00 / 0$
}

nals or the presence of obstructions at the sight of injury. The importance of extracellular cues in vivo is clearly illustrated by the ability of peripheral nerve grafts to support central axonal regrowth (Richardson et al., 1980; David and Aguayo, 1981; Aguayo et al., 1990), the growth inhibitory effect of myelinrelated proteins (Caroni and Schwab, 1988; Schnell and Schwab, 1990), the formation of central scar tissue (Reier et al., 1983; Rudge and Silver, 1990; Bovolenta et al., 1992), and the positive influence of neurotrophic factors (Hagg et al., 1990; Schnell et al., 1994).

The capacity of central axons to regenerate is lost during the early stages of mammalian development (Kalil and Reh, 1982; Fawcett et al., 1989). Moreover, axons that are able to regenerate following a pyramidal tract lesion in neonatal hamsters or cats, are found to grow around the lesion site (Kalil and Reh, 1982; Bregman and Goldberger, 1983). Although regeneration is absent in adult mammals, short distance $(<500 \mu \mathrm{m})$ collateral axonal sprouting is observed in many central locations (Liu and Chambers, 1958; Raisman and Field, 1973). In addition, in vitro experiments have demonstrated that adult rat retinal ganglion cells are able to extend processes on a growth-promoting substrate (Ford-Holevinski et al., 1986; Bähr et al., 1988).

In this study, the ability of central axons to grow through a lesion site was assessed in an explant culture system of the auditory midbrain. The inferior colliculus (IC) serves as an obligatory relay for almost all ascending and descending pathways in the central auditory system (Oliver and Huerta, 1992, for review). An intercommissural projection between the two lobes of the IC (Aitkin and Philips, 1984; Coleman and Clerici, 1987; Saldaña and Merchán, 1992) offers several advantages for the study of regeneration. The commissural afferents are present very early in development (Ramon y Cajal, 1911), they form a topographic projection (Saldaña and Merchán, 1992), and they are easily explanted as an intact pathway within a transverse section. In the present study, the culture conditions were designed to assess the regenerative capacity of postnatal commissural axons to cross a lesion site. The regenerating axons were not provided with an artificial growth-promoting substrate and, therefore, were required to grow across the sitc where their axons had been severed. The extent of axonal regeneration was assessed at 1-2 weeks postlesion, along with the distribution of glial cells within the explant cultures.

\section{Materials and Methods}

Organotypic culture. Gerbils (Meriones unguiculatus) of 6-8 d postnatal were used to produce static interface explant cultures (Stoppini et al., 
1991) of the inferior colliculus. All of the explant procedures were performed under a laminar flow hood (Baker), and the equipment was UV irradiated for at least $4 \mathrm{hr}$ prior to the generation of cultures. The microdissection tools and glassware were sterilized in ethanol and flamed, or were presterilized disposable plastic. Gerbil pups were deeply anesthetized with hypothermia (Sanes et al., 1992), the brain was rapidly removed, and the midbrain was vibratome sectioned at $300 \mu \mathrm{m}$ in Minimum Essential Medium (MEM) at $4^{\circ} \mathrm{C}$.

Unmanipulated IC slices with an intact commissure were passed through 3 drops of fresh MEM, and then transferred onto $12 \mathrm{~mm}$ filter inserts (Millipore). Manipulated slices were completely transected at the midline with a scalpel blade, and the cut edges were then reapposed on a filter insert. The inserts were placed in 24 well plates containing $\approx 350$ $\mu 1$ of culture medium $(25 \%$ Horse Serum, $50 \%$ Minimum Essential Medium, 25\% Earle's Balanced Salt Solution, $0.5 \mathrm{gm} / 100 \mathrm{ml}$ glucose, and $1 \% 200 \mathrm{~mm}$ L-glutamine; GIBCO). Each of the media components were prefiltered at $0.22 \mu \mathrm{m}$ (Falcon). The multiwell plate was placed in a humidified incubator (Forma) with $5 \% \mathrm{CO}_{2}$ at $36.5^{\circ} \mathrm{C}$, and the inserts were transferred to fresh media every $24 \mathrm{hr}$. To prevent excessive glial cell and fibroblast proliferation, the explants were exposed to a medium containing $10 \mu \mathrm{M}$ 5-fluoro-2'-deoxyuridine (Sigma), $10 \mu \mathrm{M}$ uridine (Sig$\mathrm{ma}$ ), and $10 \mu \mathrm{M}$ cytosine B-D-arabinofuranoside (Sigma) for $24 \mathrm{hr}$ at 4 $\mathrm{d}$ in vitro.

Labeling cultured neurons. To label IC neurons or their axonal projections, small crystals of biocytin (Sigma) were applied to one lobe, and the tracer was allowed to transport for approximately $12 \mathrm{hr}$ (KenanVaknin et al., 1992). The tissue was fixed for $24 \mathrm{hr}$ in a solution of $4 \%$ paraformaldehyde in $0.1 \mathrm{M}$ phosphate buffer (PBS), rinsed in PBS, and the endogenous peroxidase was quenched in $1 \% \mathrm{H}_{2} \mathrm{O}_{2}$. The tissue was then preincubated in $0.5 \%$ Triton $\mathrm{X}-100$ for $1 \mathrm{hr}$, and then incubated in avidin-biotin-horseradish peroxidase complex (ABC-HRP, Vector Labs) for $2 \mathrm{hr}$ (Horikawa and Armstrong, 1988). The tissue was washed in $0.1 \mathrm{M}$ Tris buffer solution, incubated in diaminobenzidine (DAB; 50 $\mathrm{mg} / 100 \mathrm{ml}$ Tris buffer) for $15 \mathrm{~min}$, and then reacted in a DAB solution with $\mathrm{H}_{2} \mathrm{O}_{2}$.

To verify that the commissure was present prior to the age of explantation (6-8 d postnatal), animals of 5-6 d postnatal were deeply anesthetized with hypothermia (Sanes et al., 1992), and one of the collicular lobes was injected with a $10 \%$ solution of dextran-conjugated biotin (Molecular Probes). The animals were gradually warmed on a heating pad until respiration and motor activity resumed, and were returned to the nest for $12 \mathrm{hr}$. The animals were then deeply anesthetized with sodium pentobarbital $(80 \mathrm{mg} / \mathrm{kg})$, and perfused intracardially with $4 \%$ paraformaldehyde. Following a PBS wash, $50 \mu \mathrm{m}$ vibratome sections were obtained and processed with $\mathrm{ABC}-\mathrm{HRP}$ as described above.

Immunohistochemistry. IC explants were fixed and processed as described above prior to incubation in a primary antibody overnight at room temperature. For immunohistochemistry on in vivo tissue, gerbils at postnatal days 6 and 15 were perfused with $4 \%$ paraformaldehyde, as described above, and the brain was then removed and stored in the same fixative overnight. For the GFAP immunostaining, brains were passed through a gradient of sucrose, and frozen sectioned on a sledge microtome at $40 \mu \mathrm{m}$. For MAG immunostaining, brains were vibratome sectioned at $40 \mu \mathrm{m}$.

A polyclonal antibody directed against the Tau protein (provided by Dr. A. Fellous, CNRS, Paris) was used to visualize axonal fibers in vitro (Fellous et al., 1986). A monoclonal antibody directed against glial fibrillary acidic protein (mouse anti-GFAP; Sigma) was used to stain astrocytes in vivo and in vitro (Debus et al., 1984). A monoclonal antibody directed against myelin-associated glycoprotein (mouse anti-MAG, provided by Dr. M. Schachner, Swiss Federal Institute of Technology, Zurich) was used to stain oligodendrocytes in vivo and in vitro (Poltorak et al., 1987). The sections were washed in PBS, incubated in a biotinylated secondary antibody for $3 \mathrm{hr}$ (goat anti-rabbit for Tau, and goat anti-mouse for GFAP and MAG; Sigma), washed in PBS, and incubated in ABC-HRP for $2 \mathrm{hr}$. The peroxidase was visualized with DAB as the substrate, as described above. Sections were then rinsed, allowed to airdry, dehydrated, and mounted for microscopic observations.

Electron microscopy. Biocytin injected transected IC explants were fixed in a solution of $1 \%$ paraformaldehyde and $1 \%$ glutaraldehyde in phosphate buffer. The biocytin was visualized as described above, except that the Triton concentration was reduced to $0.05 \%$. The sections were postfixed in $1 \%$ osmium tetroxide, dehydrated in alcohol, and embedded in epoxy resin. Ultrathin sections were stained with lead citrate solution and were observed under a JEOL microscope.

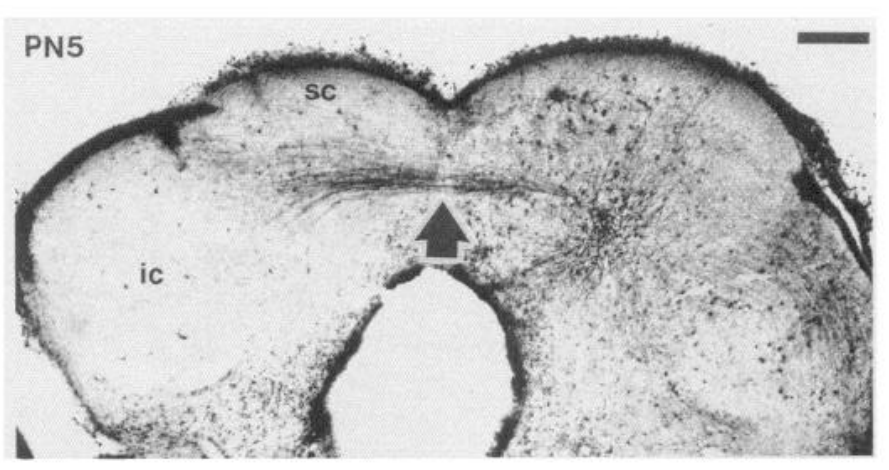

Figure 1. Biotin-labeled commissural axons from a $5 \mathrm{~d}$ old animal injected in vivo. This transverse section shows both lobes of the inferior colliculus $(I C)$, as well as a small portion of the superior colliculus (SC). The commissural projection (arrow) courses between the two lobes of the IC. Scale bar, $300 \mu \mathrm{m}$.

\section{Results}

\section{Untransected IC commissure}

To determine whether the IC intercommissural projection was present in vivo prior to the earliest age of explantation (PND 6), a small volume of $10 \%$ dextran-biotin was injected into one lobe of the IC at postnatal day 5-6. As shown in Figure 1, the commissural fibers were present, and formed a well-defined projection that crossed the midline by postnatal day 5 .

Biocytin crystals, placed within one lobe of unmanipulated IC explants, were found to label axons that projected both within the injected side and to the contralateral lobe. The large number of labeled fibers projecting to the contralateral lobe formed a well-defined tract, and followed a direct course to their termination, as did in vivo commissural axons (Fig. 2A). Biocytinlabeled neurons were found throughout the IC, and displayed a healthy dendritic morphology (Fig. $2 B, C$ ). Axons within the injected lobe were typically found to course radially, forming a fascicle that ran near the edge of the explant (Fig. $2 A$ ). There were a small number of collaterals that emanated from the commissural fibers near the midline, suggesting some limited de novo growth. Neural processes were never seen to grow beyond the edge of transected or untransected IC explants.

\section{Transected IC commissure}

Following transection of the IC commissure, and reapposition of the two lobes, the wound healed within a few days. At 7-15 d postlesion, a crystal of biocytin was placed in one lobe of the IC, and the labeled neurons displayed dendritic morphologies similar to those of the untransected explants. However, dendritic arborizations were not quantified.

As shown in Figure 3, there was robust axonal growth, both within the injected lobe, and across the lesion site. Biocytinlabeled regenerating axons were observed in $78 \%(N=46)$ of the transected explants. The regenerating fibers crossed the lesion site at all loci along the former dorsoventral axis. The major difference between regenerated and normal commissural fibers concerned the trajectories of their projections. Rather than following a normal direct course, some regenerated fibers grew along the lesion site for a short distance before extending into the contralateral IC lobe (Fig. $4 A, B$ ). In addition, many axons grew along the edge of the tissue to enter the contralateral IC lobe, and some failed to invade the central lobe. The long distance over which regenerating axons extended is illustrated by 


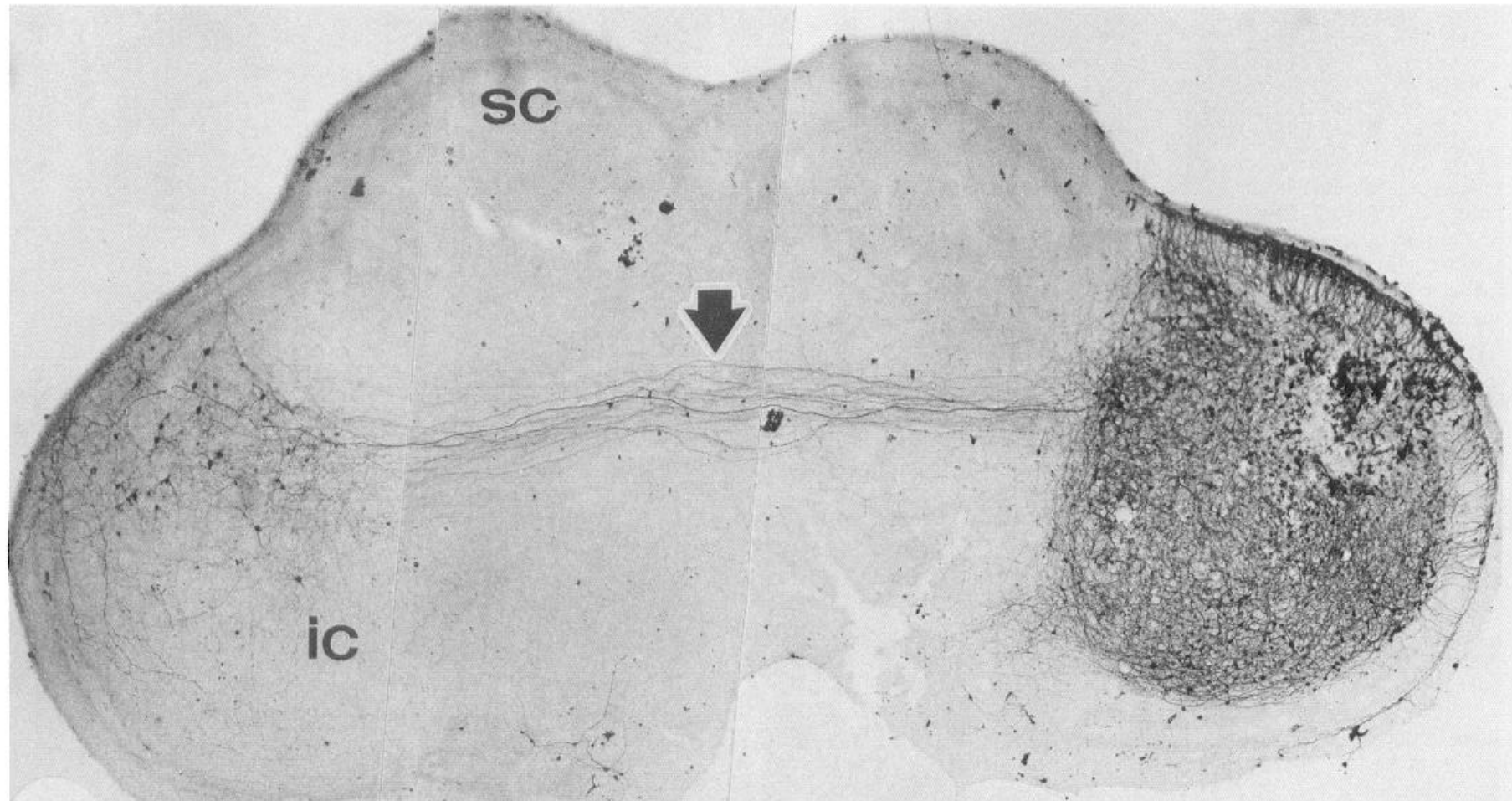

A
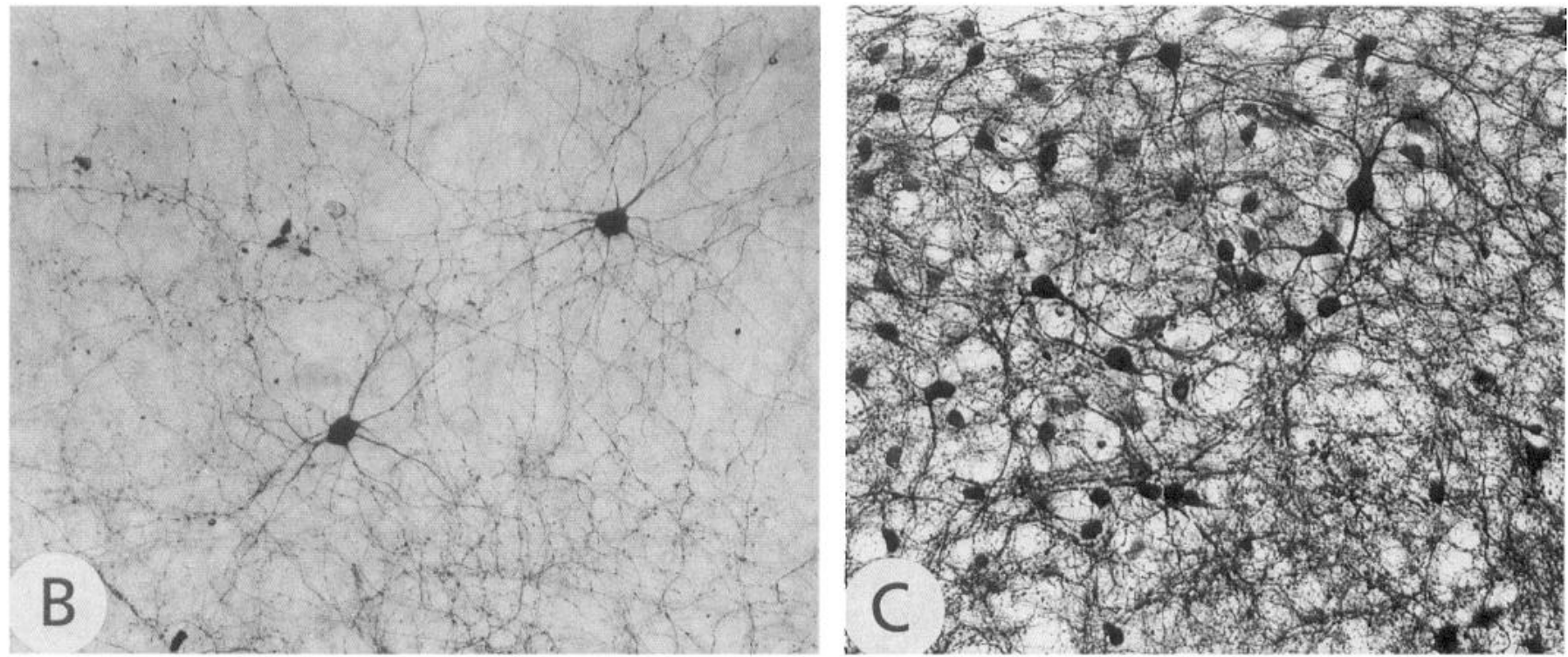

Figure 2. Explant of untransected midbrain showing biocytin-filled neurons and axons. $A$, Both lobes of the inferior colliculus (IC), as well as a small portion of the superior colliculus $(S C)$ are present. IC commissural axons transverse the slice from the injected side on the right to the left (arrow). On the biocytin-injected side, a large number of fibers were found to course radially towards the edge of the tissue, and form a fascicle. On the contralateral side, many retrogradely labeled neuronal somata are seen. $B$, High power micrograph contralateral to the injected lobe illustrates the morphology of some retrogradely labeled neurons and anterogradely labeled axonal arborizations. $C$, High power micrograph of neuronal morphology near the injection site. The tissue was obtained from a PND 6 gerbil, and grown for 10 DIV prior to biocytin labeling. Scale bar: 250 $\mu \mathrm{m}$ in $A, 43 \mu \mathrm{m}$ in $B$, and $43 \mu \mathrm{m}$ in $C$.

reconstructions of biocytin-labeled commissural fibers from a normal and a transected explant (Fig. 5). Only six arbors from unmanipulated and transected explants were drawn, so it was not possible to determine the variability of outgrowth.

To further characterize the extent of regeneration, explants were stained with an antibody directed against Tau to localize all axonal processes. As shown in Figure 4, $C$ and $D$, Tau was found to label neuronal processes throughout the explant. In all of the manipulated explants examined $(N=9)$, Tau-labeled regenerating fibers were found coursing across the entire lesion site, although there were clearly regions of high or low fiber density. The pronounced Tau immunoreactivity suggests that 


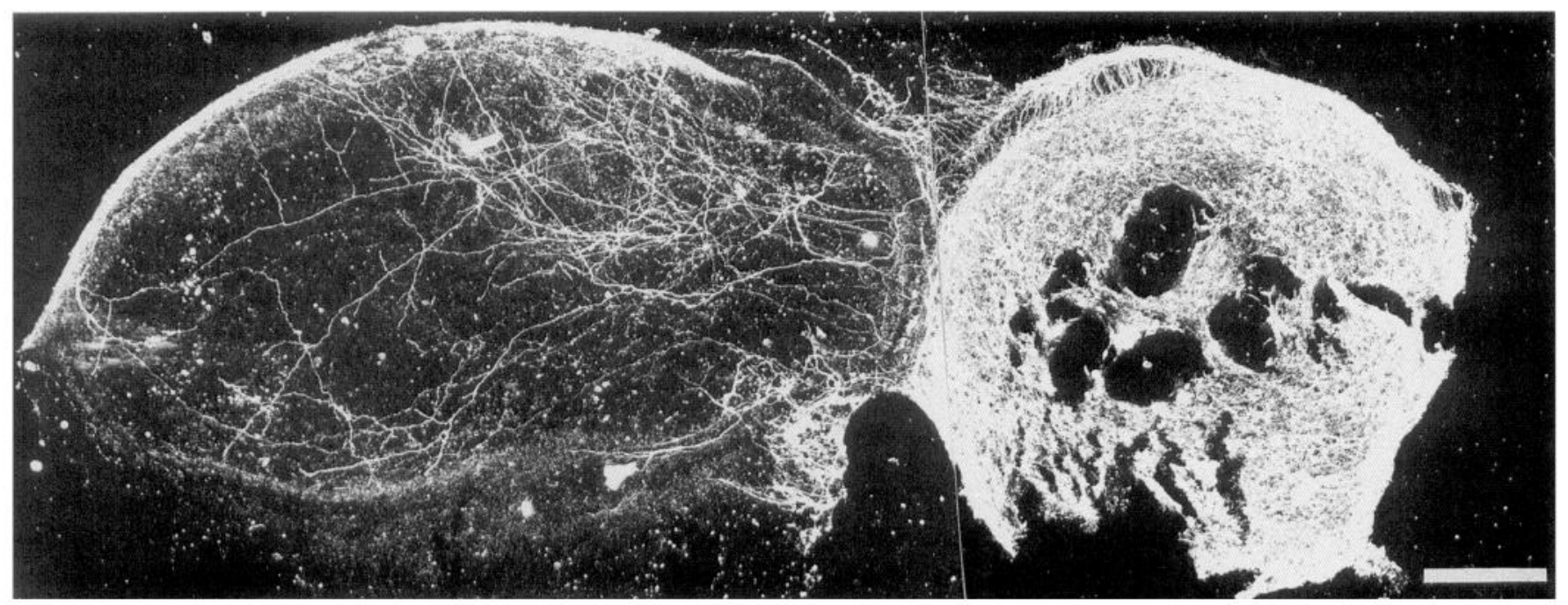

Figure 3. Regenerated axons in a transected IC explant observed in dark field. Biocytin crystals were placed in the right lobe, and filled fibers are seen to project into the left IC lobe. Some fibers grew along the edge of the contralateral IC nucleus before arborizing inside the center of the nucleus. Scale bar, $340 \mu \mathrm{m}$.

our failure to observe regeneration in $28 \%$ of the biocytin-labeled cultures was due to failed transport of biocytin.

In order to determine whether regenerated axons made synaptic contacts, biocytin-filled sections were processed for electron microscopy $(N=4)$. As shown in Figure 6, well-defined synaptic terminals were found in the contralateral IC lobe. Both unlabeled (Fig. $6 A$ ) and biocytin-labeled terminals (Fig. 6B) were present within the neuropil. The biocytin labeled terminals on the contralateral side represent regenerating fibers crossing from the injected side and innervating the contralateral side. However, unlabeled terminal on the contralateral side may represent synapses within the same IC lobe or unlabeled terminal from the contralateral IC lobe.

\section{Glial distribution in vivo and in vitro}

The distribution of GFAP-expressing astrocytes in vivo and in vitro was determined immunohistologically with an antibody directed against this intermediate filament protein. At postnatal day 6 in vivo, GFAP immunostaining was observed at the midline, along the edge of the IC and in the subventricular region (Fig. $7 A$ ). The astrocyte processes were radially oriented along the midline (Fig. 7B). The pattern of GFAP staining changed little by postnatal day 15 . GFAP-positive fibers remained most prominent at the midline, and were otherwise restricted to the edge of the IC (Fig. $7 E, F$ ). In marked contrast to the staining pattern of in vivo tissue, intense GFAP immunoreactivity was observed throughout all IC explants (Fig. $7 C, D$ ). GFAP immunoreactivity was also located at the lesion site, and GFAPpositive astrocyte processes were associated with areas exhibiting the greatest axonal outgrowth along the edge of the explant (compare Figs. $4 C, 7 C$ ).

The distribution of oligodendrocytes in vivo and in vitro was determined immunohistochemically with an antibody directed against myelin-associated glycoprotein (MAG). A very slight MAG immunoreactivity was observed at postnatal day 6 in vivo, generally around the ventral edge of the IC central nucleus (box in Fig. 8A). This MAG immunoreactivity was observed in a few oligodendrocyte cell bodies and processes (Fig. 8B). By postnatal day 15 in vivo, MAG immunoreactivity of oligoden- drocytes was extensive in the IC nuclei and along the intercommissural fibers (Fig. 8C). At high power, oligodendrocyte cell bodies and processes as well as axonal fibers were labeled (Fig. $8 D$ ). In explants grown for 8-10 d in vitro, MAG immunoreactivity was observed largely in immature oligodendrocyte cell bodies and their processes (Fig. $8 E, F$ ). There were no differences in staining pattern between the untransected and transected explants.

\section{Discussion}

The present results demonstrate that auditory midbrain tissue from postnatal day 8 gerbils can be maintained for at least 2 weeks in vitro. The morphology of dendritic arbors, and the projections of commissural axons remained robust during this period. Furthermore, IC axons were able to regenerate across the midline following complete transection of the intercommissural pathway in vitro. These findings indicate that postnatal mammalian central neurons retain the capacity to regrow through a lesion site, and do not necessarily require a growth promoting substrate.

\section{Regeneration of central axons}

The degree of axonal growth following injury decreases rapidly with age in mammals. Moreover, when regeneration is examined in vivo in the postnatal rat, hamster, opossum, and cat, the growing axons are found to avoid the lesion site (Kalil and Reh, 1982; Bernstein and Stelzner, 1983; Bregman and Goldberger, 1983; Xu and Martin, 1991). In the neonatal rat spinal cord, the ability of newly arriving or regenerating axons to grow past a lesion site declined from birth to postnatal day 6 , and regeneration did not occur after postnatal day 12 (Bernstein and Stelzner, 1983). In the hamster, the regenerative capacity decreased markedly from 8 to $12 \mathrm{~d}$ postnatal, and was virtually absent at $20 \mathrm{~d}$ (Kalil and Reh, 1982). More recently, it has been demonstrated that axons extend through a lesion of the opossum spinal cord grown in vitro during the early postnatal period (Treherne et al., 1992; Woodward et al., 1993). While growth occurs in roughly half of the preparations injured at postnatal days $3-6$, only a small percentage exhibited growth at postnatal 

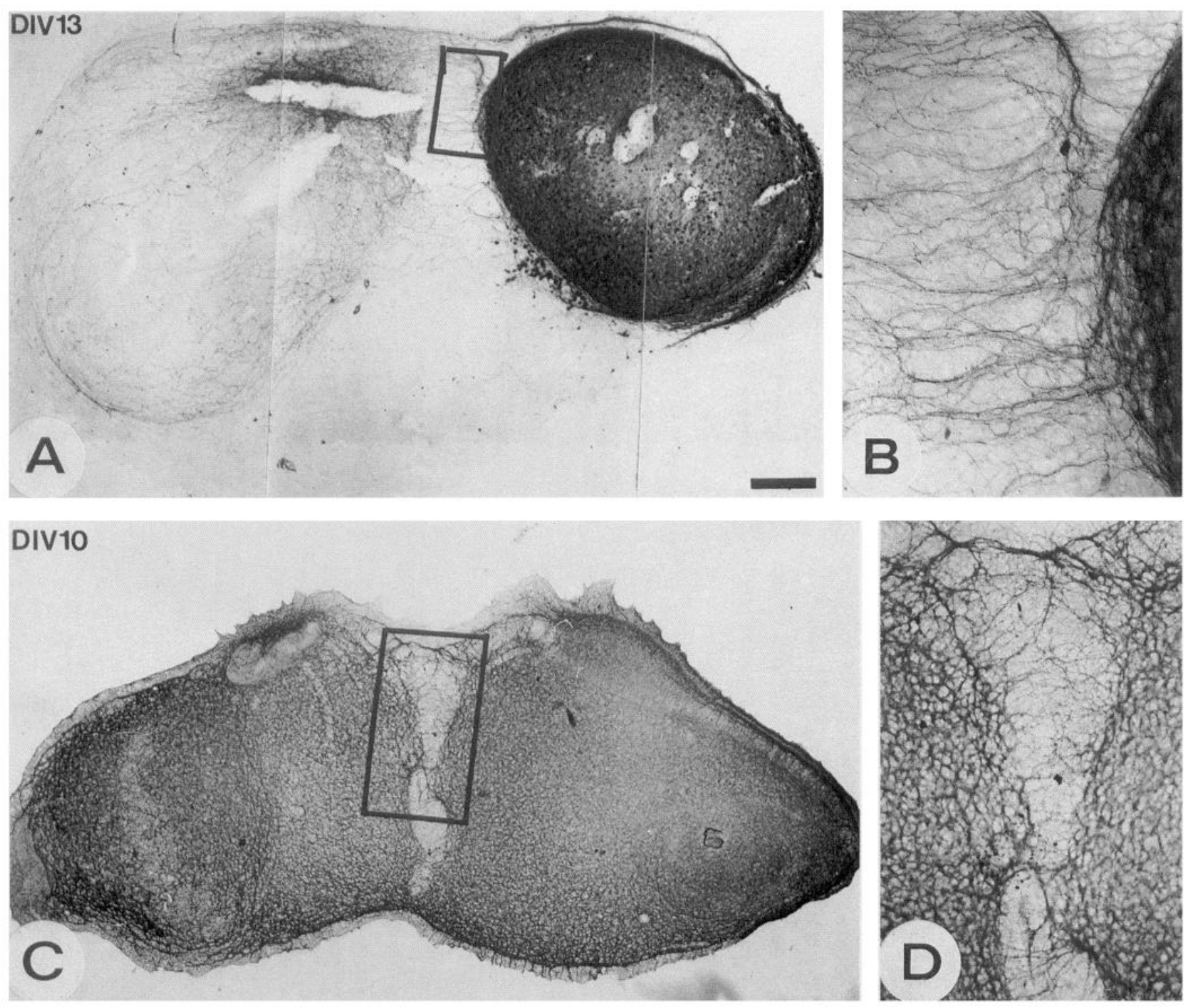

Figure 4. Transected IC explants stained with biocytin $(A)$, and the Tau antibody $(B)$. $A$, Biocytin crystals were placed in the right lobe, and labeled fibers were observed to cross the lesion site to innervate the left lobe $13 \mathrm{~d}$ after explantation and transection of the commissure. $B$, At high magnification, labeled fibers emerge from the labeled IC and course towards the left lobe. $C$, Tau immunoreactivity in transected explants was observed throughout both IC lobes $10 \mathrm{~d}$ after explantation and transection of the commissure. $D$, High magnification photomicrograph of the midline lesion site shows Tau immunoreactive fibers passing through the lesion site. Scale bar: $237 \mu \mathrm{m}$ in $A$, $75 \mu \mathrm{m}$ in $B$, and $346 \mu \mathrm{m}$ in $C$, and $140 \mu \mathrm{m}$ in $D$.

days 11-14, correlating with the first expression of growth-inhibitory factors in the spinal cord (Schwab et al., 1993; Varga et al., 1993).

The data presented here demonstrate that regenerating IC axons were able to grow across a lesion site when given no other choice. A robust axonal growth through the lesioned commissure was demonstrated with both an anterograde tracer (Figs. 3, 4A), and immunohistochemically (Fig. 4C). However, regrowing axons did not have direct trajectories, as did normal commissural afferents. Rather, the axons often became oriented along the edge of the lesion for a short distance before growing to the other lobe of the IC (Fig. $4 B, D$ ). Nevertheless, the regenerating axons were able to form de novo synapses (Fig. 6). Since our techniques for visualizing axons did not allow us to compare cell body position with termination zone, it was not possible to determine whether regenerating axons selectively arborized in any particular region of the IC.

The observed de novo axonal growth could represent sprouting of uninjured interneurons, but we consider this to be less likely. Sprouting commonly occurs when uninjured axons grow a short distance $(<500 \mu \mathrm{m})$ within a nucleus that has been partially denervated (Lund and Lund, 1973; Lynch et al., 1976; Cotman et al., 1981; Robson, 1981; Tsukahara, 1981; Goldberg et al., 1993). In the present study, axons that grew across the lesion were found to extend a considerable distance (Fig. 5). In addition, the vast majority of neurons in manipulated explants must have had severed axons, as they normally project outside of the structure (i.e., ascending, descending, and commissural afferents). The only neurons that could have remained uninjured would be interneurons projecting within the $300 \mu \mathrm{m}$ width of 

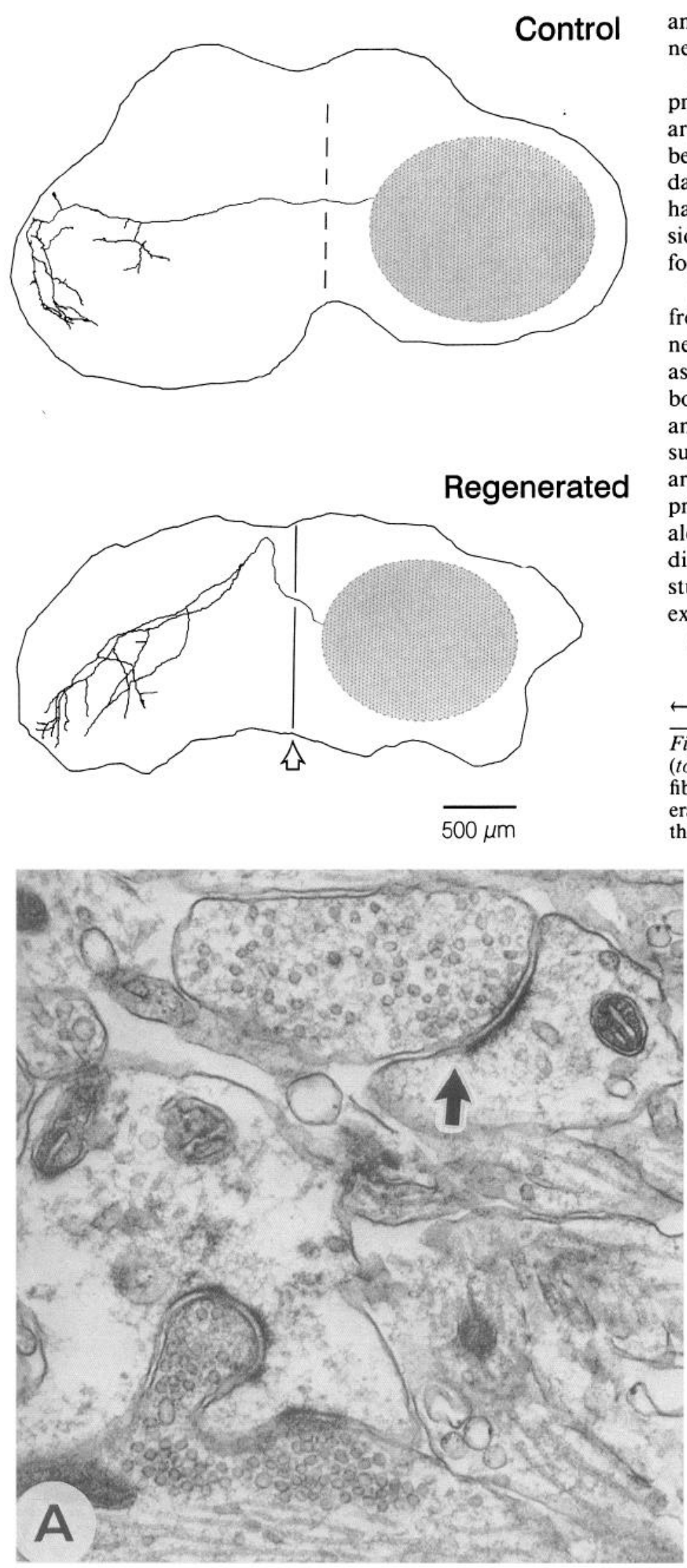

an IC slice. Such a hypothetical interneuronal population has never been described in the IC in vivo.

It is also conceivable that some IC neurons have not yet projected to the contralateral lobe at the time of explant, and are actually growing out for the first time. We consider this to be less likely because IC neurons are born between embryonic days 15-21 in the rat (Altman and Bayer, 1981), and would have to delay outgrowth along this short projection for a considerable length of time. Nevertheless, this possibility must be formally tested.

It is more likely that some of the regenerating axons emanated from neurons that do not ordinarily innervate contralateral IC neurons in vivo. The commissure of the IC normally includes ascending fibers projecting to the contralateral medial geniculate body (Rockel and Jones, 1973; Kudo and Niimi, 1978; Aitkin and Philips, 1984; Oliver, 1984), and these ascending commissural afferents may regenerate along their natural pathway, but arborize in the only available neuropil. Most of the ascending projections from the IC pass through the brachium of the IC along the lateral border, and a large number of fibers grew radially and fasciculated along this edge of the explant. Future studies in which specific neuronal populations labeled prior to explantation will be necessary to resolve this issue.

Several studies suggest that neurons lose the ability to traverse

Figure 5. Reconstruction of single biocytin labeled fibers from control (top) and regenerated (bottom) explants. In control explants, crossing fibers had straight trajectories toward the contralateral lobe. In regenerated explants, many fibers were observed to course along the edge of the injected IC lobe before crossing the lesion site.

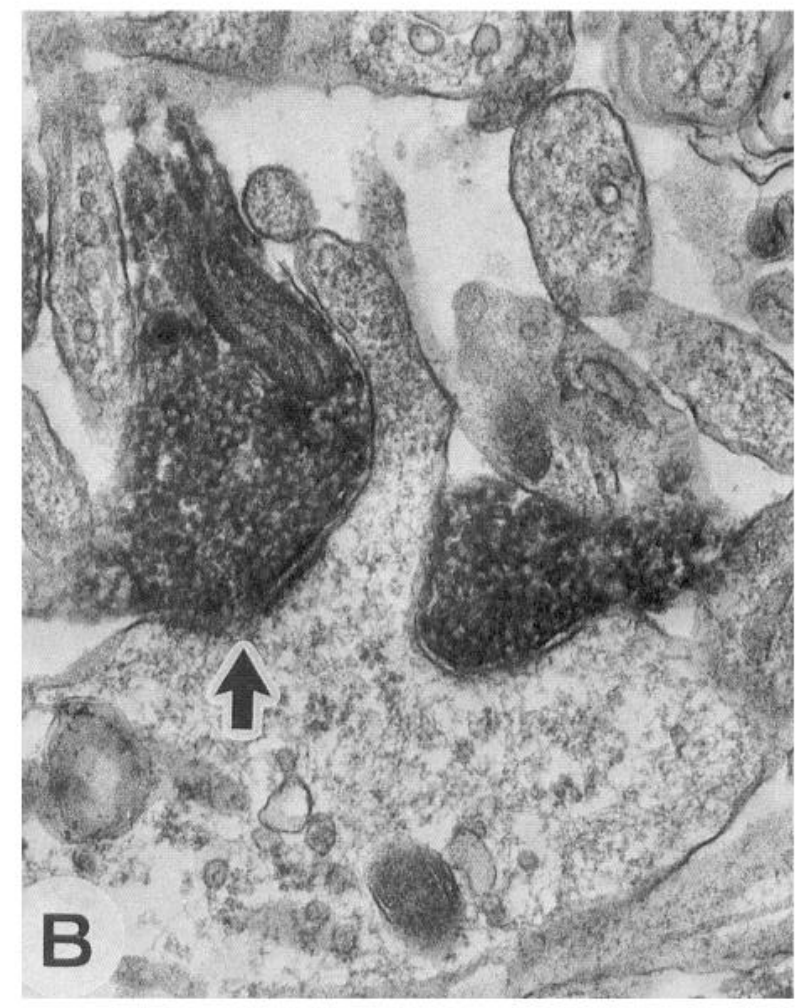

Figure 6. Biocytin-labeled terminals of regenerated axons. A, Unlabeled terminal (arrow) with numerous synaptic vesicles. This terminal may represent an intrinsic synapse within the same IC lobe or an unlabeled terminal from the injected IC lobe. $B$, Biocytin labeled terminal (arrow) with numerous synaptic vesicles. This terminal arises from a fiber emerging from the biocytin-injected lobe that crossed the lesion site. Magnification, 29,400 . 

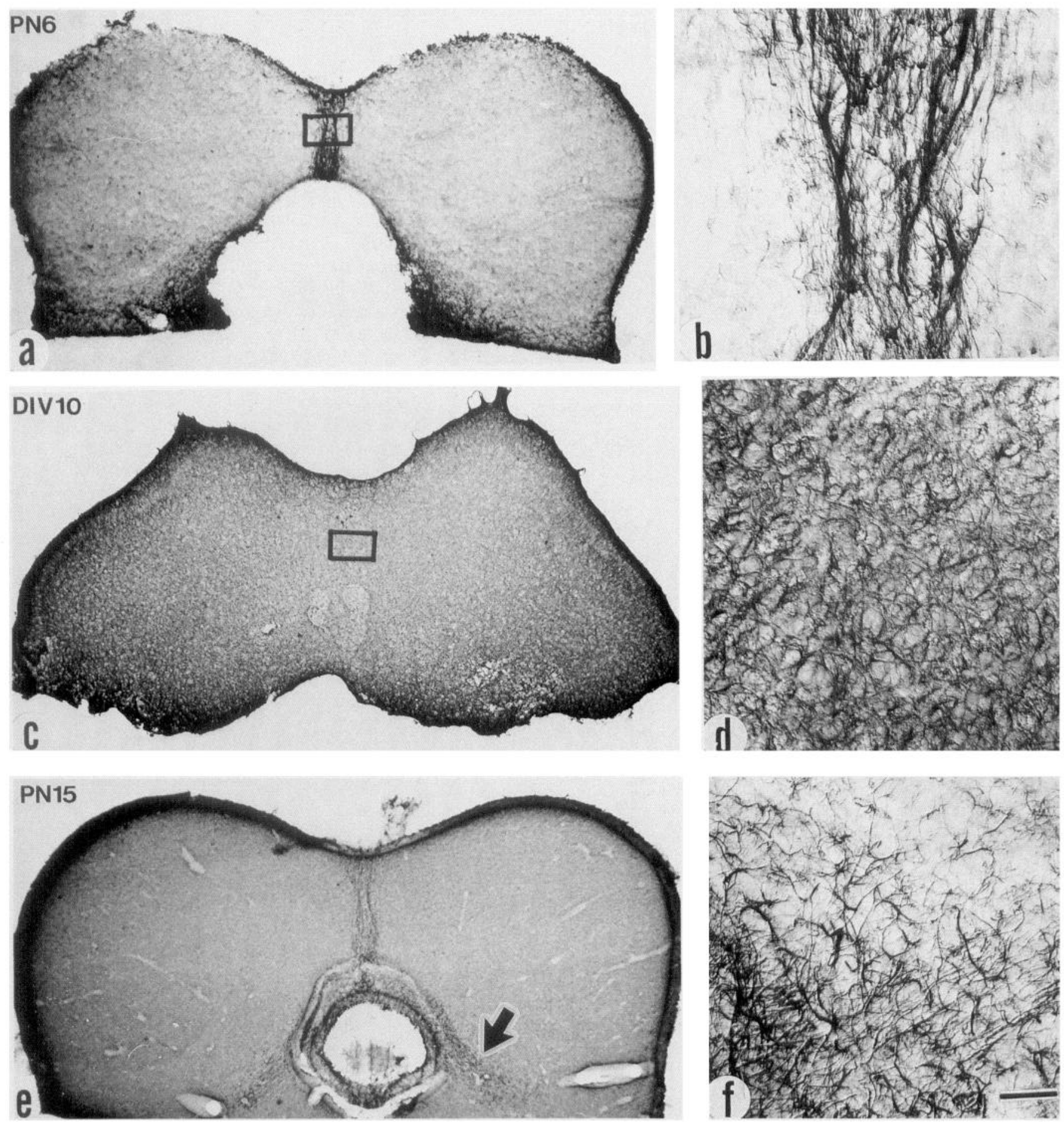

Figure 7. GFAP immunoreactivity in vivo and in vitro. A, In vivo GFAP immunoreactivity at postnatal day 6 was localized to the midline and the edge of the IC. Immunoreactivity was not observed inside the IC nucleus. $B$, At high magnification, GFAP immunoreactive processes coursed radially along the midline. $C$, In vitro GFAP immunostaining in a transected explant was located throughout the explant. $D$, At high magnification, GFAP immunoreactivity was found to intensely label astrocytic processes. $D$, In vivo GFAP immunostaining at postnatal day 15 was localized to the midline and the periphery of the IC (arrow). $F$, At high magnification, the edge of the IC exhibited labeled astrocytes. Scale bar: $365 \mu \mathrm{m}$ in $A$, $90 \mu \mathrm{m}$ in $B, 375 \mu \mathrm{m}$ in $C, 90 \mu \mathrm{m}$ in $D, 333 \mu \mathrm{m}$ in $E, 90 \mu \mathrm{m}$ in $F$ ).

adult extracellular environments as they mature (Aguayo, 1985). Human neuroblasts are able to form long axon pathways when transplanted into excitotoxin-lesioned adult rat striatum (Wictorin et al., 1990). In a similar manner, mouse embryonic retinal ganglion cells are able to grow long distances within the rostral midbrain of neonatal rats, and selectively innervate some normal targets (Radel et al., 1990). However, when provided with a suitable growth-promoting substrate, adult retinal ganglion cells are able to extend axonal processes and innervate an appropriate target in vitro (Bahr and Eschweiler, 1991). 

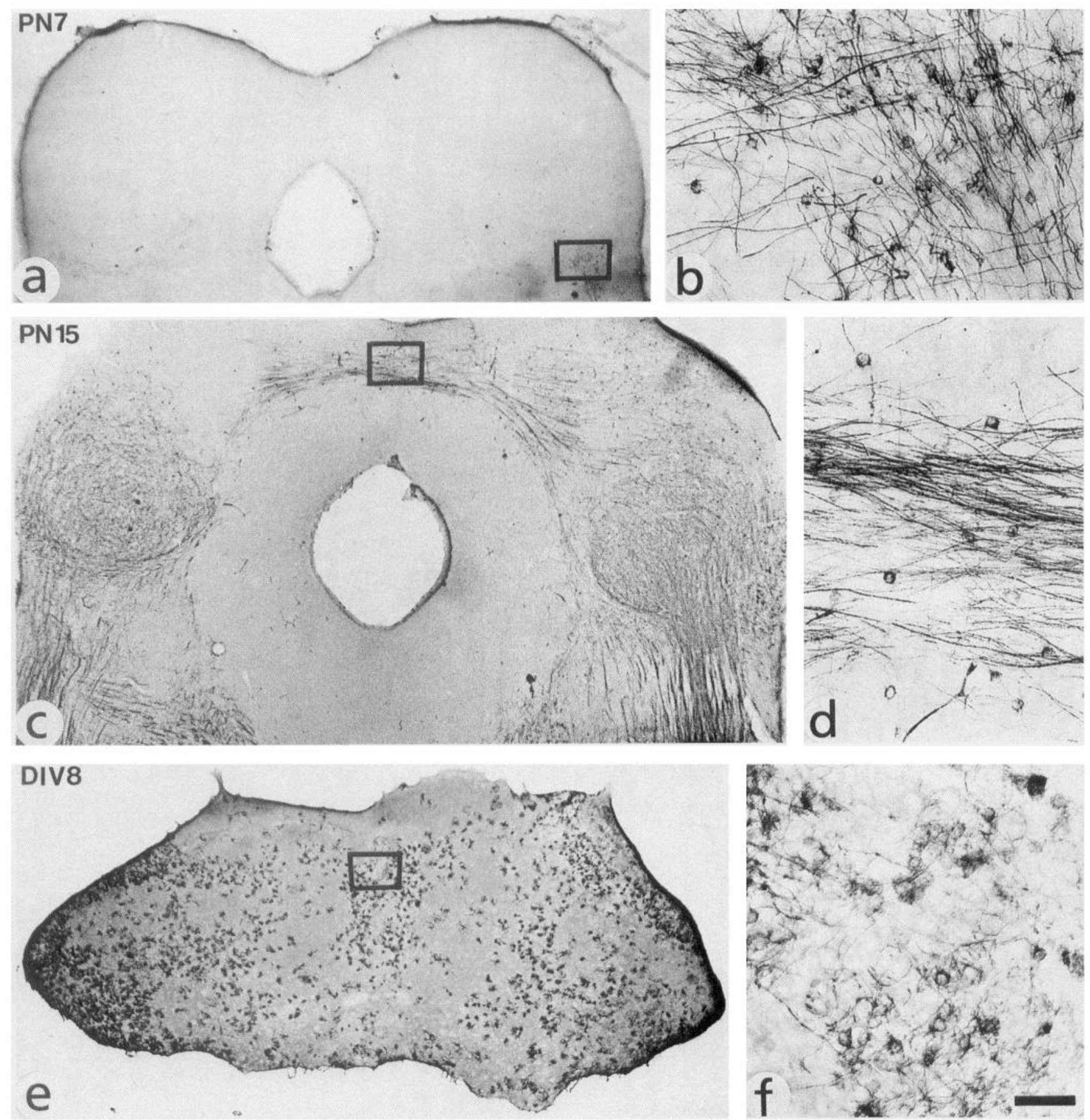

Figure 8. MAG immunoreactivity in vivo and in vitro. A, MAG immunostaining was only observed at the IC nucleus boarder at postnatal day 7 (box). B, At higher magnification, MAG staining was observed only at the ventral edge of the IC within oligodendrocyte cell bodies and their processes. $C$, At postnatal day 15, MAG immunostaining was found inside the IC nucleus contained within oligodendrocyte somata and in fibers appearing to run along neuronal projections. $D$, At high magnification, MAG-stained oligodendrocyte cell bodies and fibers were observed at the commissure. $E$, An explant at $8 \mathrm{~d}$ in vitro exhibited a uniform distribution of MAG-positive oligodendrocytes. $F$, At high magnification, MAGpositive oligodendrocytes exhibited short processes, typical of immature cells. Scale bar: $500 \mu \mathrm{m}$ in $A, 50 \mu \mathrm{m}$ in $B, 430 \mu \mathrm{m}$ in $C, 27 \mu \mathrm{m}$ in $D, 410$ $\mu \mathrm{m}$ in $E, 33 \mu \mathrm{m}$ in $F$.

\section{Glial cell distribution}

The growth-promoting and growth inhibiting actions of glial cells have been well documented (for review, see Carbonetto, 1991), and it was important to determine the distribution of oligodendrocytes and astrocytes in the cultured IC. GFAP staining of in vivo tissue was scarce, even at postnatal day 15 . The most prominent staining was found at the midline, where
$\mathrm{GFAP}^{+}$fibers were oriented radially. In contrast, all IC explant cultures were uniformly stained with GFAP by $8 \mathrm{~d}$ in vitro. These results indicate that astrocytes become reactive in our cultures, in agreement with previous studies (Fedoroff et al., 1982; Eng et al., 1992). Although the GFAP staining of in vitro tissue was associated with areas of greatest axon outgrowth near the edge of the explant, the present experiments provide no direct evidence for a causal relationship. 
Previous studies have shown that regenerating neurites can grow across reactive astrocytes in early postnatal stages (Kliot et al., 1990; Geisert and Stewart, 1991; McKeon et al., 1991), and that neonatal astrocytes provide a good substrate for neuronal process outgrowth (Silver et al., 1982; Noble et al., 1984; Fallon, 1985; Smith et al., 1986; McLoon ct al., 1988; Gasser and Hatten, 1990). We would speculate that reactive astrocytes play a role in the regeneration of commissural axons in the explant system described above. Astrocytes are also known to synthesize and release laminin (Liesi et al.,1983) a molecule that is prominent in glial scars following injury (Liesi, 1985). Laminin usually provides a growth-promoting substrate for CNS axons (Rogers et al., 1983). Astrocytes also produce neuronal outgrowth and survival factors in culture (Ferrara et al., 1988; Manthorpe et al., 1986).

The oligodendrocyte marker, MAG, was virtually absent at postnatal day 6 in vivo, but was present throughout the commissure by postnatal day 15 . In contrast, $\mathrm{MAG}^{+}$oligodendrocytes remained immature in form at $8-10 \mathrm{~d}$ in vitro. Oligodendrocytes are known to inhibit axonal growth (Berry, 1982; Savio and Schwab, 1989), and specific myelin-associated membrane proteins have been shown to inhibit neurite outgrowth in vitro (Caroni and Schwab, 1988). The small number of $\mathrm{MAG}^{+}$processes that were present in vitro suggest that the growth inhibitory effects of myelin are not a major factor during commissural regeneration. It is possible that our culture conditions may prevent oligodendrocyte maturation.

In conclusion, we have shown that postnatal mammalian central axons can display substantial regrowth through a lesion site in vitro, and that these regenerating axons are able to form synapses in the target region. The regeneration of axonal processes was well correlated with an increase of reactive astrocytes, and an arrested oligodendrocyte maturation.

\section{References}

Aguayo AJ (1985) Axonal regeneration from injured neurons in the adult mammalian central nervous system. In: Synaptic plasticity (Cotman CW, ed), pp 457-484. New York: Guilford.

Aguayo AJ, Bray GM, Rasminsky M, Zwimpfer T, Carter D, VidalSanz M (1990) Synaptic connections made by axons regenerating in the central nervous system of adult mammals. J Exp Biol 153:199224.

Aitkin LM, Philips SC (1984) The interconnections of the inferior colliculus through their commissure. J Comp Neurol 228:210-2126.

Altman J, Bayer SA (1981) Time of origin of neurons of the rat inferior colliculus and the relations between cylogenesis and tonotopic order in the auditory pathway. Exp Brain Res 42:411-423

Bähr M, Eschweiler GW (1992) Formation of functional synapses by regenerating adult rat retinal ganglion cell axons in midbrain target regions in vitro. J Neurobiol 24:456-473.

Bähr M, Vanselow J, Thanos S (1988) In vitro regeneration of adult rat ganglion cell axons from retinal explants. Exp Brain Res 73:393401 .

Bernstein DR, Stelzer DJ (1983) Plasticity of the corticospinal tract following midthoracic spinal injury in the postnatal rat. J Comp Neurol 221:382-400.

Berry M (1982) Post-injury myelin-breakdown products inhibit axonal growth: an hypothesis to explain the failure of axonal regeneration in the mammalian central nervous system. Bibl Anat 23:1-11.

Bovolenta P, Wandosell F, Nieto-Sampedro M (1992) CNS glial scar tissue: a source of molecules which inhibit central neurite outgrowth. Prog Brain Res 94:367-379.

Bregman BS, Goldberger ME (1983) Infant lesion effect. III. Anatomical correlates of sparing an recovery of function after spinal cord damage in newborn and adult cats. Brain Res 285:137-154.

Carbonetto S (1991) Facilitatory and inhibitory effects of glial cells and extracellular matrix in axonal regeneration. Curr Opinion Neurobiol 1:407-413.

Caroni P, Schwab ME (1988) Two membrane protein fraction from rat central myelin with inhibitory properties for neurite growth and fibroblast spreading. J Cell Biol 106:1281-1288.

Coleman JR, Clerici WJ (1987) Sources of projections to subdivisions of the inferior colliculus in the rat. J Comp Neurol 262:215-226.

Cotman CW, Nieto-Sampedro M, Haris EW (1981) Synapse replacement in the nervous system of adult vertebrates. Physiol Rev 61:684784.

David S, Aguayo AJ (1981) Axonal elongation into PNS ‘bridges' after CNS injury in adult rats. Science 214:931-933.

Debus E, Weber K, Osborn M (1984) Monoclonal antibodies specific for glial fibrillary acidic (GFA) protein and for each of the neurofilament triplet polypeptides. Differentiation 25:193-203.

Eng LF, Yu ACH, Lee YL (1992) Astrocytic response to injury. Prog Brain Res 94:353-365.

Fallon J (1985) Preferential outgrowth of CNS neurites on astrocytes and Schwann cells as compared to non glial cells in vitro. J Cell Biol 100:198-207.

Fawcett JW, Housden E, Smith-Thomas L, Meyer RL (1989) The growth of axons in three-dimensional astrocyte cultures. Dev Biol 135:449-458.

Fedoroff S, White RV, Neal J, Subraihmanyan L, Kalnins VI (1983) Astrocyte lineage. V. Mouse fibrous astrocytes and reactive astrocytes in culture have vimentin and GFP-containing intermediate filaments. Dev Brain Res 7:303-315.

Fellous A, Ohayon R, Mazie JC, Rosa F, Luduena RF, Prasad V (1986) Tau microheterogeneity: an immunological approach with monoclonal antibodies. Ann NY Acad Sci 466:240-256.

Ferrara N, Ousley F, Gospodawicz D (1988) Bovine brain astrocytes express basic fibroblast growth factor, a neurotropic and angiogenic mitogen. Brain Res 462:223-232.

Ford-Holevinski G, Hopkins JM, McCoy JP, Agranoff BW (1986) I aminin supports outgrowth from axotimized adult retinal axons. Dev Brain Res 28:121-126.

Gasser UE, Hatten ME (1990) Neuron-glia interactions of developing rat hippocampal cells in vitro: glial guided ncuronal migration and neuronal regulation of glial differentiation. J Neurosci 10:1276-1285.

Geisert EE, Stewart AM (1991) Changing interactions between astrocytes and neurons during CNS maturation. Dev Biol 143:335-345.

Glendenning KK, Brunso-Bechtold JK, Thompson GC, Masterton RB (1981) Ascending auditory afferents to the nuclei of the lateral lemniscus. J Comp Neurol 197:673-703.

Goldberg MM, Murray M, Tessler A (1993) Sprouting and regeneration in the spinal cord. Their roles in recovery of function after spinal injury. In: Neurodegeneration (Gorio A, ed), pp 241-264. New York: Raven.

Hagg T, Vahlsing HL, Manthorpe M, Varon S (1990) Nerve growth factor infusion into the denervated adult rat hippocampal formation promotes its cholinergic reinnervation. J Neurosci 10:3087-3092.

Horikawa K, Armstrong WE (1988) A versatile means of intracellular labeling: injection of biocytin and its detection with avidin conjugates. J Neurosci Methods 25:1-11.

Kalil K, Reh T (1982) A light and electron microscopic study of regrowing pyramidal tract fibers. J Comp Neurol 211:265-275.

Kenan-Vaknin G, Katz H, Malach R (1992) Golgi-like staining of visual cortex cells obtained by extracellular biocytin application in vitro. Brain Res 571:338-341.

Kliot M, Smith GM, Siegel JD, Silver J (1990) Astrocyte-polymer implants promote regeneration of dorsal root fibers into the adult mammalian spinal cord. Exp Neurol 109:57-69.

Kudo M, Niimi K (1978) Ascending projections of the inferior colliculus onto the medial geniculate body in the cat studied by anterograde and retrograde tracing techniques. Brain Res 155:113-117.

Liesi P (1985) Laminin immunoreactive glia distinguish rcgencrative adult CNS systems from non-regenerative ones. EMBO J 4:27052511.

Liesi P, Dahl D, Vaheri A (1983) Laminin is produced by early rat astrocytes in primary culture. J Cell Biol 96:920-924.

Liu CN, Chambers WW (1958) Intraspinal sprouting of dorsal root axons. Arch Neurol Psychiatry 79:46-61.

Lund RD, Lund JS (1976) Plasticity in the developing visual system: the effects of retinal lesions made in young rats. J Comp Neurol 169: 133-154. 
Lynch G, Gall C, Rose G, Cotman CW (1976) Changes in the distribution of the dentate gyrus associational system following unilateral orbital entorhinal lesions in the adult rat. Brain Res 50:174-178.

Manthorpe M, Rudge IS, Varon S (1986) Astroglial cells contributions to neuronal survival and neuritic growth. In: Astrocytes, Vol 2 (Fedoroff S, Vernadakis A, eds), pp 315-376. New York: Academic.

Matthey $R$ (1925) Récupération de la vue après résection des nerfs optiques chez le triton. CR Soc Biol 93:904-906.

McKeon RJ, Schreiber RC, Rudge JS, Silver J (1991) Reduction of neurite outgrowth in a model of glial scarring following CNS injury is correlated with the expression of inhibitory molecules on reactive astrocytes. J Neurosci 11:3398-3411.

McLoon SC, Mcloon LK, Palm SL, Furcht LT (1988) Transient expression of laminin in the optic nerve of the developing rat. J Neurosci 8:1981-1990.

Noble M, Fok-Seang J, Cohen J (1984) Glia are unique substrate for the in vitro growth of central nervous system neurons. J Neurosci 4:1892-1903.

Oliver DL (1984) Neurons types in the central nucleus of the inferior colliculus that project to the medial geniculate body. Neuroscience 11:409-422.

Oliver DL, Huerta MF (1992) Inferior and superior colliculi. In: The mammalian auditory pathway: neuroanatomy (Webster DB, Popper AN, Fay RR, eds), pp 168-221. New York: Springer.

Piatt J (1956) Regeneration in the central nervous system of amphibia. In: Regeneration in the central nervous system (Windle WF, ed), pp 20-46. Springfield: Thomas.

Poltorak M, Sadoul R, Keilhauer G, Landa C, Fahrig T, Schachner M (1987) Myelin-associated glycoprotein, a member of the L2/HNK-1 family of neural cell adhesion molecules is involved in neuron-oligodendrocyte and oligodendrocyte-oligodendrocyte interaction. J Cell Biol 105:1893-1899.

Radel JD, Hankin MH, Lund RD (1990) Proximity as a factor in the innervation of host brain regions by retinal transplants. J Comp Neurol 300:211-229.

Raisman G, Field PM (1973) A quantitative investigation of the development of collateral reinnervation after partial deafferentation of the septal nuclei. Brain Res 50:241-264.

Ramón y Cajal S (1911) Histologie du système nervoux de l'homme et des vertébrés, Vol II, pp 153-173.

Ramón y Cajal S (1928) Degeneration and regeneration of the nervous system. Reprint (May RM, trans). Hafner: New York, 1959.

Reier PJ, Stensaas LJ, Guth L (1983) The astrocytic scar as an impediment to regeneration in the central nervous system. In: Spinal cord reconstruction (Kao CC, Bunge RP, Reier PJ, eds), pp 163-195. New York: Raven.

Richardson PM, McGuinness UM, Aguayo AJ (1980) Axons from CNS neurones regenerate into PNS grafts. Nature 254:264-265.

Robson JA, Mason CA, Guillery RW (1978) Terminal arbors of axons that have formed abnormal connections. Science 201:635-637.

Rockel AJ, Jones EG (1973) The neuronal organization of the inferior colliculus of the adult cat. I. The central nucleus. J Comp Neurol 147 : $11-60$.
Rogers SL, Letourneau PC, Palm SL, McCarthy J, Furcht LT (1983) Neurite extension of peripheral and central nervous system neurons in response to substratum bound fibronectin and laminin. Dev Biol $98: 212-220$

Rudge JS, Silver J (1990) Inhibition of neurite outgrowth on astroglial scars in vitro. J Neurosci 10:3594-3603.

Saldaña E, Merchan ME (1992) Intrinsic and commissural connections of the rat inferior colliculus. J Comp Neurol 319:417-437.

Sanes DH, Markowitz S, Bernstein J, Wardlow J (1992) The influence of inhibitory afferents on the development of postsynaptic dendritic arbors. J Comp Neurol 321:637-644.

Savio T, Schwab ME (1989) Rat CNS white matter, but not gray matter, is nonpermissive for neuronal cell adhesion and fiber outgrowth. J Neurosci 9:1126-1133.

Schnell L, Schwab ME (1990) Axonal regeneration in the rat spinal cord produced by an antibody against myelin associated neurite growth inhibitors. Nature 343:269-272.

Schnell L, Schneider R, Kolbeck R, Barde Y-A, Schwab ME (1994) Neurotrophin-3 enhances sprouting of corticospinal tract during development and after adult spinal cord lesion. Nature 367:170-173.

Schwab ME, Bandtlow CE, Varga Z, Nicholls J (1993) Developmental expression of myelin-associated neurite growth inhibitors correlates with the loss of regeneration after spinal cord lesions in the opossum. Soc Neurosci Abstr 19:682.

Silver J, Lorenz SE, Wahlsten D, Coughlin J (1982) Axonal guidance during development of the great cerebral commissures: descriptive and experimental studies, in vivo, on the role of preformed glial pathways. J Comp Neurol 210:10-29.

Smith GM, Miller RH, Silver J (1986) Changing role of forebrain astrocytes during development, regenerative failure, and induced regeneration upon transplantation. J Comp Neurol 251:23-43.

Stoppini L, Buchs PA, Muller D (1991) A simple method for organotypic cultures of nervous tissue. J Neurosci Methods 37:173-182.

Treherne JM, Woodward SKA, Varga ZM, Ritchie JM, Nichols J (1992) Restoration of conduction and growth of axons through injured spinal cord of neonatal opossum in culture. Proc Natl Acad Sci USA 89: $431-434$.

Tsukahara $N$ (1981) Synaptic plasticity in the mammalian central nervous system. Annu Rev Neurosci 4:351-379.

Varga Z, Erulkar S, Nicholls J (1993) A critical time period for growth of neurites across a lesion in neonatal opossum spinal cord in culture. Soc Neurosci Abstr 19:422.

Wictorin K, Brundin P, Gustavii B, Lindvall O, Björklund A (1990) Reformation of long axon pathways in the adult rat central nervous system by human forebrain neuroblasts. Nature 347:556-558.

Woodward SKA, Treherne JM, Knott GW, Fernandez J, Varga ZM, Nichols JG (1993) Development of connections by axons growing through injured spinal cord of neonatal opossum in culture. J Exp Biol 176:77-88.

Xu XM, Martin GF (1991) Evidence for new growth and regeneration of cut axons in developmental plasticity of the rubrospinal tract in the north American opossum. J Comp Neurol 313:103-112. 